\title{
Revealing hidden species diversity in closely related species using nuclear SNPs, SSRs and DNA sequences - a case study in the tree genus Milicia
}

Kasso Daïnou ${ }^{1,2^{*}}$ (D) Céline Blanc-Jolivet ${ }^{3}$, Bernd Degen ${ }^{3}$, Priscilla Kimani ${ }^{4}$, Dyana Ndiade-Bourobou ${ }^{5}$, Armel S. L. Donkpegan ${ }^{6}$, Félicien Tosso ${ }^{6}$, Esra Kaymak ${ }^{7}$, Nils Bourland ${ }^{8}$, Jean-Louis Doucet ${ }^{6}$ and Olivier J. Hardy ${ }^{7}$

\begin{abstract}
Background: Species delimitation in closely related plant taxa can be challenging because (i) reproductive barriers are not always congruent with morphological differentiation, (ii) use of plastid sequences might lead to misinterpretation, (iii) rare species might not be sampled. We revisited molecular-based species delimitation in the African genus Milicia, currently divided into M. regia (West Africa) and M. excelsa (from West to East Africa). We used 435 samples collected in West, Central and East Africa. We genotyped SNP and SSR loci to identify genetic clusters, and sequenced two plastid regions (psbA-trnH, trnC-ycf6) and a nuclear gene (At103) to confirm species' divergence and compare species delimitation methods. We also examined whether ecological niche differentiation was congruent with sampled genetic structure.

Results: West African M. regia, West African and East African M. excelsa samples constituted three well distinct genetic clusters according to SNPs and SSRs. In Central Africa, two genetic clusters were consistently inferred by both types of markers, while a few scattered samples, sympatric with the preceding clusters but exhibiting leaf traits of $M$. regia, were grouped with the West African M. regia cluster based on SNPs or formed a distinct cluster based on SSRs. SSR results were confirmed by sequence data from the nuclear region At103 which revealed three distinct 'Fields For Recombination' corresponding to (i) West African M. regia, (ii) Central African samples with leaf traits of $M$. regia, and (iii) all M. excelsa samples. None of the plastid sequences provide indication of distinct clades of the three species-like units. Niche modelling techniques yielded a significant correlation between niche overlap and genetic distance.

Conclusions: Our genetic data suggest that three species of Milicia could be recognized. It is surprising that the occurrence of two species in Central Africa was not reported for this well-known timber tree. Globally, our work highlights the importance of collecting samples in a systematic way and the need for combining different nuclear markers when dealing with species complexes. Recognizing cryptic species is particularly crucial for economically exploited species because some hidden taxa might actually be endangered as they are merged with more abundant species.
\end{abstract}

Keywords: Tropical forests, Milicia, Cryptic species, Species delimitation, SNP, Microsatellites, DNA sequences

\footnotetext{
* Correspondence: k.dainou@natureplus.be; kdainou@ulg.ac.be

${ }^{1}$ Nature + asbl / TERRA Research Centre, Central African Forests, Gembloux

Agro-Bio Tech, University of Liege, Passage des Déportés 2, 5030 Gembloux,

Belgium

Université d'Agriculture de Kétou, BP 43, Kétou, Benin

Full list of author information is available at the end of the article
} 


\section{Background}

Species diversification and morphological evolution are not always correlated, as demonstrated by the existence of hidden genetic diversity in taxa previously considered as single species. In sexual organisms, a cryptic species complex in the sense of [1] designates reproductively isolated species assigned to the same taxonomical species name because they are hardly distinguishable morphologically: sibling taxa with obscure morphologies [2,3]. The concept is not new: in 1942, Ernest Mayr listed several known 'sibling species' in support to his criticisms of the morphological species concept. But the prevalence of hidden diversity in various taxa has been much better appreciated in the two last decades owing to surveys of DNA variation within species or closely related species [2]. The abundance of cryptic species raises several issues. Estimating the number of species has become a challenge $[4,5]$. The use of confounding cryptic species as biological indicators or for medicinal applications can be detrimental if the cryptic species in question differ from their common allied species members in terms of their ecology or physiology. Conservation issues need to be considered for economically important species, such as timber tree species which are sometimes composed of complexes of cryptic species $[2,5]$.

Hidden genetic diversity can sometimes be detected through direct observations, suggesting for instance reproductive barrier between individuals (phenology or pollination patterns, etc.). Reproductive isolation between sympatric sibling species can be detected using genetic markers. In addition, several molecular markers are needed because different evolutionary processes such as incomplete lineage sorting can obscure the genetic divergence displayed by a single marker. DNA-based phylogenetic approaches are often used to delineate species, and reproductively isolated groups can be identified following the phylogenetic species concept if they segregate into different monophyletic lineages. However, the absence of monophyly is not conclusive because genetically isolated groups can be paraphyletic or polyphyletic [6, 7]. Hence, in order to delineate closely related species, methods that do not require monophyly would be suitable.

A variety of such methods have been proposed [3]. Flot et al. [8] suggested the construction of haplowebs of nuclear sequences to identify fields for recombination (FFR, based on the method of [9]), a FFR being a group of individuals that have haplotypes found co-occurring in heterozygotes. For this reason, the approach is not applicable on plastid or mitochondrial sequences. The FFR approach does not require monophyly and it was demonstrated that this method is among the best singlelocus methods for delimitating species especially in species-poor data sets [10]. This performance is explained by the fact that construction of FFR relies on the verification of contemporaneous gene flow among the putative species, because gene flow is a crucial issue when one deals with species delimitation following the "biological species concept". Biparentally inherited molecular markers have been widely used to estimate gene flow and to construct species phylogeny (e.g. [11-13]. This idea is reinforced by suggestion of a higher taxonomic value for nuclear markers in plants, because pollen dispersal contributes more to gene flow than seed dispersal (sole vector of gene flow for the plastid genome in most angiosperms) for most plant species [14].

Besides nuclear DNA sequences, widely used codominant markers such as nuclear microsatellites (or simple sequence repeats, SSRs) and single-nucleotide polymorphism loci (SNPs) are valuable to address population structure and species delineation in closely related taxa [15]. Assignment of genetic clusters to different species is automatic when the detected groups are found in sympatry and there is absence or scarcity of gene flow that cannot be explained by history (e.g. very recent secondary contact), ecological factors (e.g. microhabitats causing delay of phenology or existence of physical barriers) or particular breeding systems (e.g. autogamy, clonality). Guichoux et al. [16] suggested that microsatellites may be better than SNP to detect mixtures of genetic clusters (see also [17, 18]. But opposite findings have also been reported and the debate on the relative performance of SNPs over SSRs remains [19]. Ljungqvist et al. [20] suggested that using of five times more SNPs than SSRs are necessary to achieve the same discrimination power (see also $[21,22]$ ). This ratio is not a rule but should depend on the characteristics of the loci used, the number of alleles, the degree of differentiation among the studied populations, and the methods used for marker development, which can at times generate ascertainment bias [23].

Milicia is an important African timber genus that has received attention from scientists during the last decade, although the focus was on populations found in Ghana and Cameroon (see a bibliography review in [24]). Phylogeographical and phylogenetical investigations by $[25,26]$ confirmed the existence of two morphologically similar species: M. regia, found West Africa from Senegal to Ghana, and M. excelsa, found from West to East Africa and part of Austral Africa. Several lines of evidence suggest that our current phylogeographic knowledge might be incomplete. First, relying on morphological characterization, the renowned botanist Auguste Chevalier claimed that $M$. regia naturally occurs in some parts of Gabon [27]. Second, East Africa was poorly represented in [26] while it might harbour genetically original populations, as reported in other widely distributed African plant species (e.g. [28, 29]). Third, the heterogeneous sampling intensity of the previous works might have affected the power to detect distinct genetic clusters [30] so that a more systematic sampling may reveal additional patterns. In addition, the degree of 
similarity or overlap of the environmental envelopes of the inferred genetic clusters as well as the degree of correlation between genetic distances and niche overlap measures have seldom been addressed in African plant taxa, although these issues may give hints on the relative importance of neutral $v s$. adaptive forces underlying genetic differentiation between clusters [31, 32].

The present study revisits the genetic diversity of Milicia populations in Africa along with an assessment of its relationships with climate niche patterns using a more homogeneous sampling. We compare the ability of SSRs and SNPs for delimiting genetic clusters and species, and detect any hidden genetic diversity in Milicia populations, and we use a nuclear DNA sequence to assess phylogenetic relationships. More specifically, we addressed the following questions: (1) Does Milicia regia naturally occur in Central Africa as reported a century ago [27], and if so, what is the degree of divergence between the populations of the genus Milicia in Central and East Africa? (2) What is the degree of congruence between the different genetic markers in terms of population structure and history? (3) Is there any sign indicating that habitat selection may have contributed to the genetic divergence among Milicia genetic clusters?

\section{Methods}

\section{Study taxa, sampling context and sampling plan}

The genus Milicia contains two species in sympatry in West Africa: M. regia and M. excelsa. Whereas the range of $M$. regia seems to be restricted to the Upper Guinean domain, $M$. excelsa stretches in various African forest types from West to East Africa. Both species are wind pollinated and seeds are dispersed by bats and parrots [25]. Genetic evidence showed that they constitute two reproductively isolated groups despite existence of paraphyly in M. excelsa [26]. In West Africa, M. regia is considered as an endangered species due to overexploitation for timber production and deforestation, and is listed as a vulnerable species by the IUCN [24]. There is no particular logging restriction regarding the widespread $M$. excelsa in Central Africa, except for a minimum cutting diameter.

A project dedicated to wood traceability purposes has been recently achieved (ITTO Project PD 620/11 M (Rev. 1); [33]). One of its specific objectives was to document the genetic structuring in Milicia species at a higher spatial resolution than previous works that detected five geographically coherent genetic clusters [34, 35]). To this end, a systematic sampling was carried out in seven countries: Ivory Coast, Ghana, Cameroon, Gabon, Republic of the Congo, Democratic Republic of the Congo and Kenya, with 10-20 individuals sampled in grid-cells of $100-150 \mathrm{~km}$ side (depending on the country) laid out on the known range of the genus. For the present study we retained a subsample of 435 individuals distributed over the study zone (Fig. 1) which represented a substantial part of the range of the genus.

\section{Genotyping and sequencing}

These 435 individuals were genotyped at seven nuclear microsatellites following [26] and at 67 biallelic nuclear SNP loci. These SNP markers were developed using an approach of the Thünen Institute for Forest Genetics (TIFG). The method is based on a restriction associated DNA sequencing protocol (RADseq). Two samples of $M$. excelsa from Benin and Kenya were used. Libraries were prepared using the restriction enzyme $S b f l$, and sequenced on the Illumina HiSeq 2000 platform to create paired end reads of $2 \times 100$ bp. SNPs were identified in the sequenced individuals using variant call format (VCF) 4.1 (Floragenex). Marker screening was conducted in a sample comprising 95 individuals of $M$. excelsa and 16 individuals of $M$. regia in Assay Design Suite (ADS) (Agena Bioscience) and genotyped on the MassARRAY iPLEX platform (Agena Bioscience) (C. Blanc-Jolivet and B. Degen, in preparation). The same team of the TIFG contributed to the development of similar SNP markers in another African tree species in the framework of the aforementioned project and the protocol is described in [36]. SNPs have been chosen because they can be assayed using shorter DNA fragments than microsatellites, an advantage using degraded DNA extracted from wood. In a subset of 190 individuals, we further sequenced two intergenic regions of the plastid genome, $p s b A-\operatorname{trn} H$ and $\operatorname{trn} C-y c f 6$, and one genic region of the nuclear genome, At103, the only polymorphic region observed among 12 tested gene regions in Milicia [37]. The protocol for sequencing is described in [26].

\section{Genetic structure of Milicia populations and morphological differentiation of genetic clusters}

We ran TESS 2.3.1 [38] to identify genetic clusters separately using the SNPs and SSRs datasets. The protocol was as follows: the maximum number of clusters, $K_{\max }$, was fixed between 2 and 10; we chose an admixture model and the interaction parameter, $\psi$, was set to 0 (i.e. spatial information is not used to identify genetic clusters); each run consisted in 20,000 iterations with a 5000 burn-in period, and we performed 10 runs for each value of $K_{\max }$. Then for each type of markers, we plotted values of the deviance information criterion, DIC, against $K_{\max }$ to infer the likely number of clusters. The average cluster membership, $q$, of each individual was finally determined (program CLUMPP; [39]) and individuals were assigned to a given cluster when $q>0.5$. Because both SNP and SSR loci detected a questionable genetic cluster of scattered but well delimited populations into the Central African region with genetic affinities with $M$. regia, the latter being expected only in 


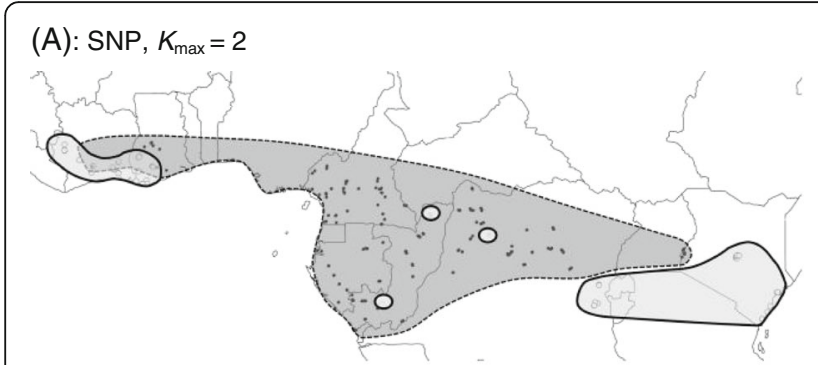

(C): SNP, $K_{\max }=3$

(B): SSR, $K_{\max }=2$

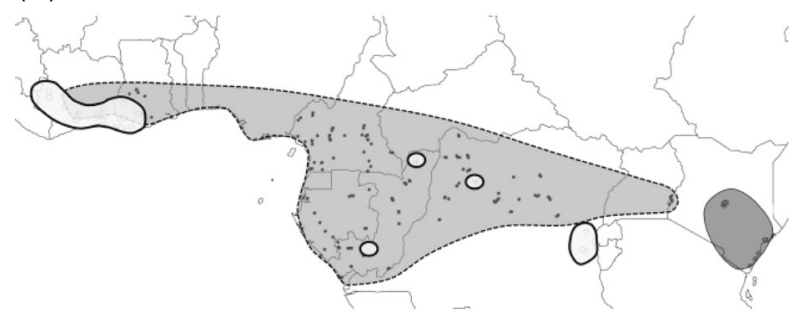

(D): SSR, $K_{\max }=3$
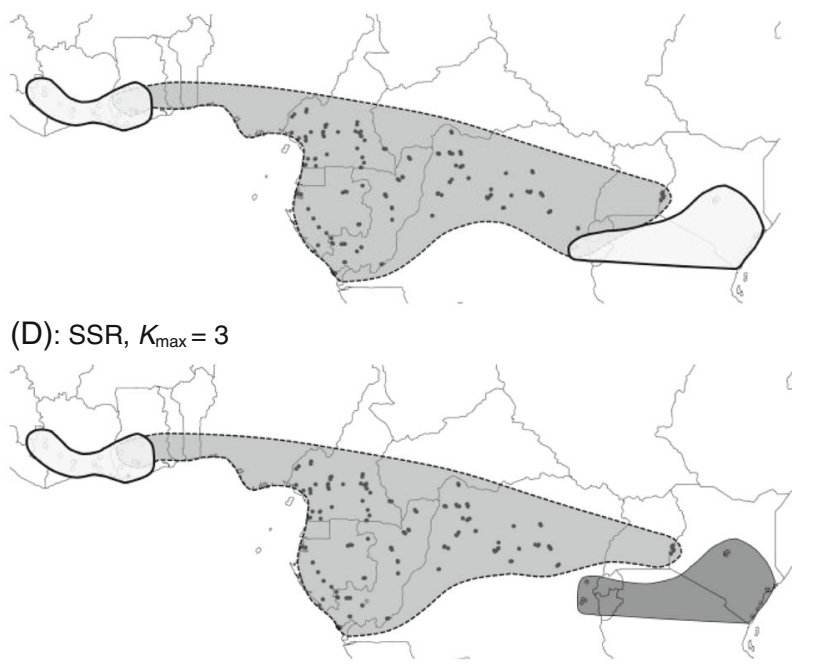

$(\mathrm{E}): \mathrm{SNP}, K_{\max }=4$

$(\mathrm{F}): \mathrm{SSR}, K_{\max }=4$
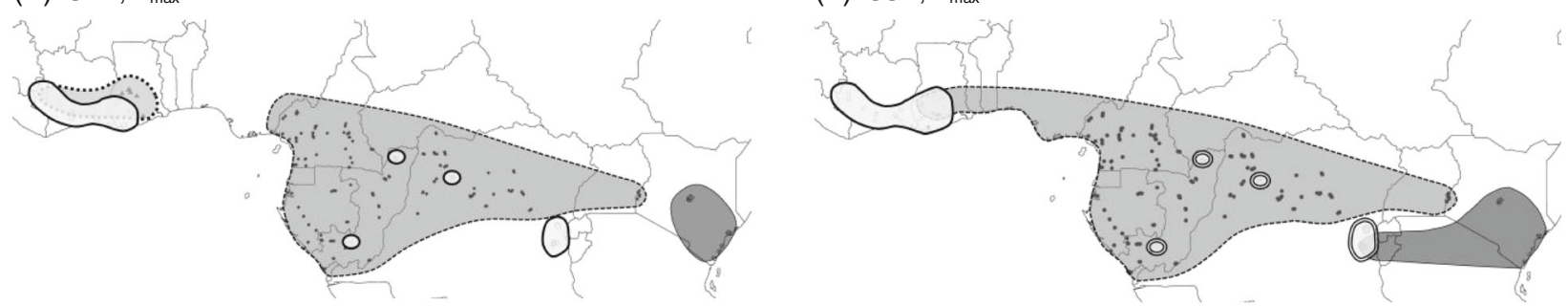

(G): SNP, $K_{\max }=5$

$(\mathrm{H}): \mathrm{SSR}, K_{\max }=5$
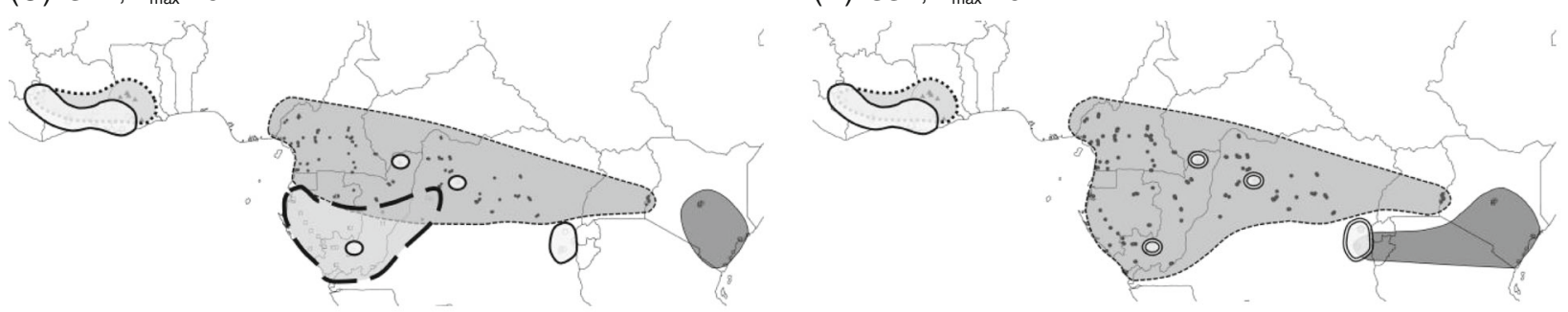

(J): SSR, $K_{\max }=6$

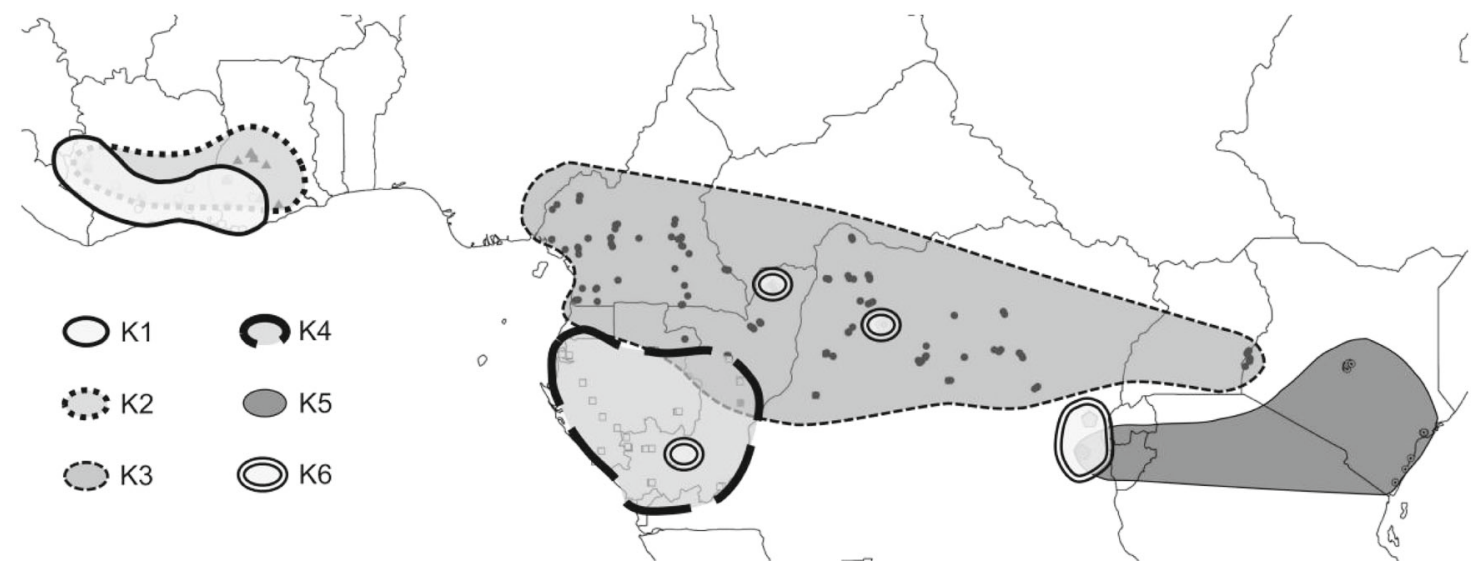

Fig. 1 Evolution of genetic clustering among 435 Milicia samples according to $K_{\max } . K_{\max }$ was increased from $2(\mathbf{a}, \mathbf{b})$ to $5(\mathbf{g}, \mathbf{h})$ and 6 (j) using nuclear SNPs (left; $\mathbf{a}, \mathbf{c}, \mathbf{e}$ and $\mathbf{g}$ ) or SSRs (right; $\mathbf{b}, \mathbf{d}, \mathbf{f}$ and $\mathbf{h}$ ). $\mathbf{j}$ shows the most likely scenario with $\mathrm{K}=6$ genetic clusters according to SSRs genotypes. Each combination of grey tone and type of outline stands for a given genetic cluster 
West Africa (see results), we also verified the leaf morphology of samples from each genetic cluster under a stereomicroscope. The lower leaf surface of adult specimens of $M$. excelsa should present microscopic hairs in contrast to $M$. regia [26].

For each inferred genetic cluster, the following diversity parameters were computed using SPAGEDI 1.4 [40]: the effective number of alleles, NAe [41], the allelic richness, $A R$ (for a given number of gene copies), and the gene diversity corrected for sample size, $\mathrm{He}$. The degree of differentiation between genetic clusters was assessed through three parameters: $F_{\mathrm{ST}}$ and Nei's standard genetic distance with sample size correction, $D_{\mathrm{S}}$, which are both allele identity based statistics, and $(\delta \mu)^{2}$ based on microsatellite allele size (hence not computed for SNPs) [42]. $D_{\mathrm{S}}$ and $(\delta \mu)^{2}$ are expected to better reflect divergence time than $F_{\mathrm{ST}}$, which depends much on genetic drift, and can be used for phylogenetic reconstruction.

\section{Phylogeny and estimate of divergence time among genetic clusters}

Microsatellites can be useful in phylogenetic reconstruction under the stepwise mutation model and mutation-drift balance (e.g., [42, 43]) even for taxa that have diverged as long as 30 mya [44]. Therefore, we verified whether the SSRsbased phylogeny of genetic clusters could confirm the phylogenies inferred from DNA sequences ( $p s b A-\operatorname{trn} H$, trnC-ycf6, and At103). Using POPTREE 2 and following [45], we constructed phylogenetic trees based on $D_{\mathrm{S}}$ and $(\delta \mu)^{2}$ computed from the SSRs data. Trees were constructed with the Neighbor-Joining method and tree validity was evaluated by bootstrapping (10,000 replications). We also estimated divergence time $t$ between pairs of genetic clusters via the equation $(\delta \mu)^{2}=2 \mu G$ [46], with $\mu$ being the mutation rate per locus per generation and $G$ the number of generations after the divergence of the two considered populations. We assumed 100 years per generation and $\mu$ ranging between $5.0 \times 10^{-6}$ and $10^{-3}$ per generation per locus for microsatellite loci $[47,48]$.

For nucleotide sequence data, we first constructed a median joining network for each sequence using NETWORK 4.6 [49]. Thereafter only the nuclear sequence At103 was employed for further analyses as plastid sequence data provided poor separation of the different genetic clusters (see results). Haplotypes were reconstructed with PHASE implemented in DnaSP [50] and CHAMPURU [51] for length variant heterozygotes. A haploweb sensu [8] was constructed by connecting haplotypes occurring in heterozygous individuals in order to identify fields for recombination (FFR). To verify congruence between SSRs data and those of the nuclear sequence At103, we also constructed a phylogenetic tree based on At103 haplotypes through the Bayesian method implemented in "BEAST [52]. From a previous analysis in [26], we dated the ancestor of Milicia at 8-41 mya ( $95 \%$ posterior estimate of the age distribution) and this was utilized as a prior for the analysis. A Yule tree prior and an uncorrelated relaxed molecular clock were assumed. The MCMC was run seven times for 500 million generations, each run being sampled every 50,000 generations, and the final tree had the highest posterior probabilities at the nodes.

\section{Modelling the environmental niche of genetic clusters and evaluating correlation between niche overlap and genetic distance}

First, we inferred putative geographical locations of each genetic cluster detected with TESS 2.3.1 [38] through environmental niche modelling using Maxent [53] with the logistic methods and the default settings for the maximum entropy. Last Glacial Maximum (LGM, 21,000 years ago) climatic variables obtained at 2.5 arc-minute resolution from the WorldClim global dataset [54] were considered for niche modelling. Principal component analysis (PCA) was used as a data reduction technique to avoid model over-fitting linked to correlated predictor variables [55]. We retained a $500 \mathrm{~km}$-buffer zone to the whole dataset in order to reach the known limits of Milicia range in Africa and because this gave the best models based on preliminary values of the Area Under the Curve (AUC; from 0.89 to 0.97 ). Analyses were performed with the $\mathrm{R}$ environment [56].

Second, we applied a smoothing technique through a PCA that divides the environmental space (delimited by the minimum and the maximum climatic values) in cells and uses a kernel function to determine the smoothed density of occurrence for each genetic cluster to each cell $i\left(100-\mathrm{km}^{2}\right.$ each) [57]. Then we computed the metric $D$ developed by [58] for pairwise niche overlap $(D=1-$ $0.5 \sum\left|p_{\mathrm{X}, \mathrm{i}}-p_{Y, \mathrm{i}}\right|$ where $p_{\mathrm{X}, \mathrm{i}}$ and $p_{Y, \mathrm{i}}$ stand for the probability assigned by the ENM (Environmental Niche Modelling) for genetic clusters $X$ and $Y$, respectively, to cell $i$ ). The statistic $D$ varies from 0 (no overlap between the two considered niches) to 1 (the two niches are identical). Finally, the correlation between genetic distances as expressed by $D_{\mathrm{S}}$ or $(\delta \mu)^{2}$ from SSRs and niche overlap measure $D$, was tested by the means of a simple Mantel test in order to verify whether niche overlap was higher - or not - in genetically similar clusters. Recent studies revealed that genetic divergence of specific gene markers can be a good predictor of differentiation at quantitative trait loci in random mating populations [31]. That is, divergence in neutral loci can reflect adaptive phenotypic selection (reviewed in [32]). Hence any significant correlation between $D$ and $D_{\mathrm{S}}$ or $(\delta \mu)^{2}$ may reflect a genetic signature of divergent selection across some genetic clusters of Milicia, especially those in the Congo Basin where climate is quite similar across a large region. We 
chose genetic divergence measures from SSRs because they are superior at elucidating the genetic structure of Milicia populations (results). A total of 10,000 permutations were performed for testing the significance of the Mantel tests.

\section{Results}

Genetic clustering from SSRs vs SNPs: evidence of a closely related taxon of $M$. regia in Central Africa

When applying genetic clustering using the SNP dataset the increment of the likelihood of the data with $K_{\max }$ displayed a steep positive slope to $K_{\max }=4$ followed by a shallower positive slope with $K_{\max }$ without an asymptotic trend (Additional file 1: Figure S1). Using the SSR dataset the substantial increase of likelihood occurs up to $K_{\max }=6$ where an asymptote seems to be reached (Additional file 1: Figure S2). The clustering patterns defined geographically coherent genetic clusters (with one exception discussed later) and were globally congruent between SNPs and SSRs, except that the order at which the genetic clusters appeared as $K_{\max }$ increased differed between types of markers (Fig. 1). SNPs and SSRs clustering patterns were globally congruent when $K_{\max }=5$ for SNPs (Fig. 1g) and $K_{\max }=6$ for SSRs (Fig. 1j). The main difference is that one of the SNPs genetic clusters was divided into two clusters according to SSRs: one in West Africa, K1, and another one in Central Africa, K6.

The West African individuals of $M$. regia formed one genetic cluster named K1. West African individuals of $M$. excelsa formed another cluster named K2. Both types of markers also identified a large genetic cluster of $M$. excelsa, $\mathrm{K} 3$, stretching from the forest zone of Cameroon to the Northern parts of the Republic of the Congo (RC) and Democratic Republic of the Congo (DRC). A genetic cluster K4 covered the Western part of Gabon and appeared only at $K_{\max }=5$ for the SNPs and $K_{\max }=6$ for the SSRs (Fig. 1). A fifth genetic cluster, K5, covered Kenya (and the East of DRC based on the SSR dataset). The main difference between the two types of markers was the finding of 13 Central African individuals that were assigned to cluster K1 (M. regia) according to SNPs (Fig. 1g) whereas SSRs grouped 12 of these individuals in a new genetic cluster that we named K6 (Fig. 1j; Table 1). Contrary to the other clusters which display distinct distributions, K6 displays a disjoint spatial distribution largely embedded in the range of clusters K3 and K4.

Regarding the order of appearance of genetic clusters as $K_{\max }$ increases, according to SNPs, the Central African assigned-to-K1 individuals appeared as soon as $K_{\max }$ was fixed to 2 , whereas these same individuals (with the exception of one tree) were isolated from the largest Central African cluster only at $K_{\max }=4$ according to SSRs (Fig. 1). Another important difference came from the genetic cluster $\mathrm{K} 2$ grouping West African $M$. excelsa: it was detected at $K_{\max }=4$ with the SNPs, and at $K_{\max }=$ 5 with the SSRs. Both types of markers grouped Kenyan individuals with West African $M$. regia individuals at $K_{\max }=2$, but distinguished them at $K_{\max }=3$. SNPs and SSRs detected the Gabonese cluster K4 only at their final respective scenario (5 clusters for SNPs and 6 for SSRs). As the most questionable genetic cluster was $\mathrm{K} 6$ given its disjoint distribution and its inclusion in K1 (M. regia) according to the SNPs, we verified the morphology of all individuals from that genetic cluster and samples from the neighbouring genetic clusters. Our observations confirmed that all the 13 individuals identified as $M$. regia according to the SNP display the specific leaf feature of M. regia (Additional file 1: Figure S3). Individuals in genetic clusters $\mathrm{K} 2$ to $\mathrm{K} 5$ harbour microscopic hairs characteristic of $M$. excelsa.

Finally, when using TESS to evaluate the genetic structure among the M. regia genetic clusters, K1 of West Africa and K6 of Central Africa, SNPs and SSRs markers were congruent, identifying two clusters (Fig. 2), with no evidence of admixture according to SSRs, in contrast to the results from the SNPs (bias likely due to the low diversity of SNPs in M. regia, and thus limited information content to distinguish genetic clusters) (Fig. 2). Even when

Table 1 Number of individuals assigned to each cluster at $q=0.50$ for SNP and SSR analyses. Numbers in bold in the diagonal indicated individuals jointly assigned by SNPs and SSRs to a same genetic cluster

\begin{tabular}{|c|c|c|c|c|c|c|c|c|c|}
\hline & \multicolumn{9}{|c|}{ SSRs genetic clusters } \\
\hline & & K1 & K2 & K3 & K4 & K5 & K6 & Undefined & Total \\
\hline \multirow[t]{8}{*}{ SNPs genetic clusters } & K1 & 44 & 4 & 3 & & 1 & & 10 & 62 \\
\hline & K2 & 1 & 30 & 4 & & & & 2 & 37 \\
\hline & K3 & & & 197 & 17 & 3 & & 2 & 219 \\
\hline & K4 & & & 5 & 67 & & & & 72 \\
\hline & K5 & & & 1 & & 30 & & & 31 \\
\hline & K6 & & & & & & 12 & 1 & 13 \\
\hline & Undefined & & & & & & & 1 & 1 \\
\hline & Total & 45 & 34 & 210 & 84 & 34 & 12 & 16 & 435 \\
\hline
\end{tabular}


(A)

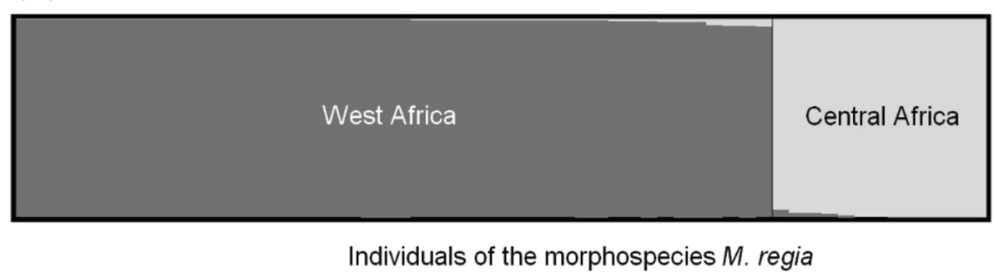

(B)

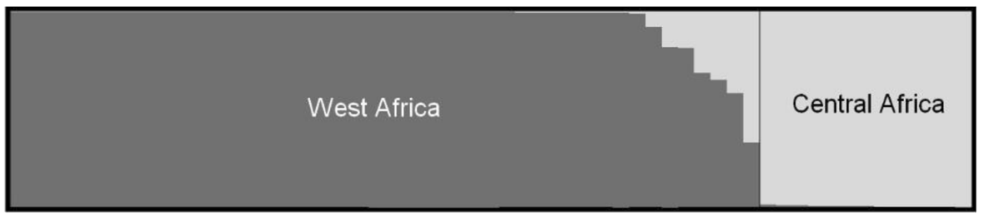

Individuals of the morphospecies $M$. regia

Fig. 2 Membership coefficient of individuals that present leaves of M. regia. $\mathbf{a}$ was based on SSRs whereas $\mathbf{b}$ was based on SNPs. $K_{\max }=2$ was considered for both figures

we considered only Central African clusters of Milicia, there was no evidence of substantial gene flow between K6 and the surrounding populations (Additional file 1: Figure S4). Hence even for the SNPs, we will consider thereafter morphological $M$. regia individuals of Central Africa as forming a sixth genetic cluster.

\section{Congruence of SNPs and SSRs in estimating diversity and differentiation parameters}

A total of 380 of the 435 individuals analysed were jointly assigned to the same genetic clusters by both types of markers, making an average concordance of $87 \%$ (Table 1). In order to reliably compare SSRs and SNPs we considered only these 380 individuals for the estimates of diversity and differentiation parameters. SSR loci provided a total of 65 alleles whereas the 67 biallelic SNP loci provided 134 alleles (allele ratio $\mathrm{SNP} / \mathrm{SSR}=2.06$ ). Values of diversity parameters tend to be lower with the SNPs than the SSRs due to the biallelic state of the SNPs. The trends among types of markers were similar if we consider only genetic clusters of the morphospecies $M$. excelsa: the Kenyan cluster, K5, displayed the lowest values whereas genetic diversity was in the same order for the other clusters K2, K3 and K4. Markers differed strikingly when comparing the two species: SSR data provided the highest diversity values for the West African M. regia genetic cluster, K1, while SNPs displayed the opposite trend, with the clusters of $M$. excelsa exhibiting the highest diversity values (Table 2). The proportion of polymorphic SNP loci in M. excelsa was $100 \%$ whereas it reached 72 and $22 \%$ in $M$. regia genetic clusters $\mathrm{K} 1$ and $\mathrm{K} 6$, respectively (Table 2; Additional file 1: Table S1).

There were also significant differences between SNPs and SSRs in estimating degree of genetic divergence in pairs of genetic clusters. For $F_{\mathrm{ST}}$, the values calculated from SNPs were higher than those from SSRs (Wilcoxon Matched Pairs test; $Z=2.38, P=0.017$ ); that trend was reversed if we considered $D_{\mathrm{S}}$ (Wilcoxon test; $Z=3.24, P=0.001$ ). As expected from divergent evolution in the clustering pattern (Fig. 1), the two measures of genetic differentiation between clusters were not strongly correlated with a coefficient of determination $R^{2}=0.13$ for $D_{\mathrm{S}}$ and $R^{2}=0.41$ for $F_{\mathrm{ST}}$ (Fig. 3). There was nonzero y-intercept (Fig. 3). Finally, we considered the pair of $M$. regia genetic clusters, $\mathrm{K} 1$ and $\mathrm{K} 6$ to compare $F_{\mathrm{ST}}$ and $D_{\mathrm{S}}$ (Fig. 2). Whereas SNPs $F_{\mathrm{ST}}$ reached 0.57 for that pair (the global pairwise $F_{\mathrm{ST}}$ was 0.56 ), $D_{\mathrm{S}}$ for the same pair of genetic clusters was 0.09 (the global pairwise $D_{\mathrm{S}}$ of 0.47 ) (Table 3 ). In general $D_{\mathrm{S}}$ better reflected the clustering pattern and was better correlated to $(\delta \mu)^{2}$ in microsatellites than did $F_{\mathrm{ST}}$ (Pearson's $R=0.74$ for $D_{\mathrm{S}}-(\delta \mu)^{2}$ vs. $\mathrm{R}=0.55$ for $F_{\mathrm{ST}^{-}}(\delta \mu)^{2}$ (from data in Table 3).

\section{Phylogenetic reconstruction in Milicia genetic clusters}

For the two chloroplast regions, $p s b A-\operatorname{trn} H$ and $\operatorname{trn} C-y c f 6$, only the $M$. regia genetic cluster in West Africa (K1)

Table 2 Diversity parameters among the six inferred genetic clusters in Milicia populations. NAe effective number of alleles, $A R$ allelic richness, and He gene diversity corrected for sample size, Np/ proportion of polymorphic SNP loci

\begin{tabular}{|c|c|c|c|c|c|c|c|c|}
\hline \multirow{2}{*}{$\begin{array}{l}\text { Genetic } \\
\text { clusters }\end{array}$} & \multirow{2}{*}{$\begin{array}{l}\text { Sample } \\
\text { size }\end{array}$} & \multicolumn{3}{|l|}{ SSRs } & \multicolumn{4}{|c|}{ SNPs } \\
\hline & & $\mathrm{NAe}$ & $A R$ & $\mathrm{He}$ & $\mathrm{NAe}$ & $A R$ & $\mathrm{He}$ & $\mathrm{Npl}$ \\
\hline K1 & 44 & 3.93 & 2.71 & 0.7243 & 1.08 & 1.06 & 0.0632 & 0.72 \\
\hline K2 & 30 & 2.33 & 2.12 & 0.5372 & 1.37 & 1.23 & 0.2283 & 0.87 \\
\hline K3 & 197 & 2.07 & 1.98 & 0.4794 & 1.56 & 1.33 & 0.3275 & 0.99 \\
\hline K4 & 67 & 2.03 & 1.89 & 0.4405 & 1.46 & 1.27 & 0.2744 & 0.91 \\
\hline K5 & 30 & 1.71 & 1.68 & 0.3181 & 1.16 & 1.12 & 0.1175 & 0.82 \\
\hline K6 & 12 & 1.98 & 1.88 & 0.4205 & 1.04 & 1.03 & 0.0297 & 0.22 \\
\hline
\end{tabular}



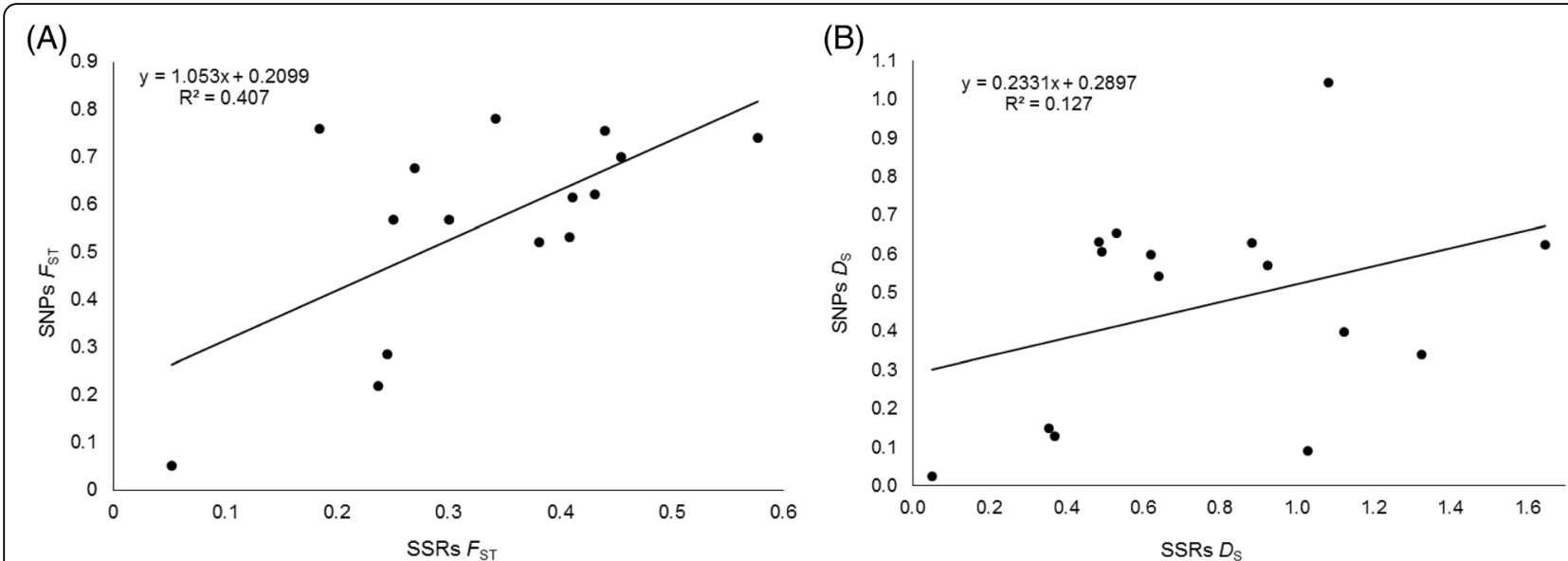

Fig. 3 Correlation between genetic differentiation estimates from SNPs and SSRs in Milicia genetic clusters. a was based on FST; $\mathbf{b}$ was based on DS

harboured specific haplotypes. Individuals of the cluster K6 shared their haplotypes with the other M. excelsa populations (Additional file 1: Figures S5 and S6).

The nuclear sequence At103 from 130 individuals exhibited a different pattern. First, individuals of the morphospecies M. regia found in central Africa (cluster K6) presented specific haplotypes, H_1 and H_14 (Fig. 4). Determination of FFR through haploweb construction confirmed that contemporaneous mating does not occur between these Central African individuals of $M$. regia and any other group of Milicia individuals (Fig. 4). $M$. regia in West Africa (genetic cluster K1) also displayed a specific FFR with eight haplotypes whereas $M$. excelsa populations from West and Central Africa (genetic clusters K2, K3, K4 and K5) shared a unique FFR (Fig. 4).

In terms of phylogenetic relationships, analyses of the nuclear sequence At103 showed that the clusters K6 and K1 (morphologically $M$. regia) tend to depart from the other genetic clusters (M. excelsa) but with a weak support (0.38; Fig. 5a). The most recent common ancestor of all genetic clusters was dated at 8.71 mya (range of 0.15 to 35.25 mya, with a confidence interval of $95 \%$ ). Both phylogenetic trees from microsatellite and SNPs data based on $D_{\mathrm{S}}$ exhibited similar trends and contrasted with the At103 scenario on one point: the relative position of the M. regia cluster K1 that showed more affinity with the genetic

Table 3 Estimates of genetic distances and niche overlap measure (D) between Milicia genetic clusters. The degree of genetic differentiation was based on $F_{S T}$, Nei's $D_{S}$ and Goldtstein's $\delta \mu^{2}$ computed from genotypes at SNP and SSR datasets

\begin{tabular}{|c|c|c|c|c|c|c|c|}
\hline \multicolumn{2}{|c|}{ Genetic clusters } & \multicolumn{3}{|l|}{ SSRS } & \multicolumn{2}{|l|}{ SNPS } & \multirow[t]{2}{*}{ Niche overlap ( $D$} \\
\hline $\bar{x}$ & Y & $\overline{\delta \mu^{2}}$ & $F_{s t}$ & $D_{s}$ & $\overline{F_{s t}}$ & $D_{s}$ & \\
\hline K1 & K2 & 2.726 & 0.185 & 0.486 & 0.759 & 0.632 & 0.180 \\
\hline K1 & K3 & 3.030 & 0.250 & 0.491 & 0.569 & 0.608 & 0.292 \\
\hline K1 & K4 & 4.328 & 0.270 & 0.531 & 0.677 & 0.655 & 0.303 \\
\hline K1 & K5 & 3.892 & 0.343 & 1.122 & 0.782 & 0.398 & 0.479 \\
\hline K1 & K6 & 10.795 & 0.301 & 1.030 & 0.568 & 0.091 & 0.046 \\
\hline K2 & K3 & 2.231 & 0.237 & 0.370 & 0.220 & 0.130 & 0.129 \\
\hline K2 & K4 & 2.876 & 0.245 & 0.356 & 0.286 & 0.150 & 0.078 \\
\hline K2 & K5 & 7.193 & 0.440 & 1.081 & 0.756 & 1.043 & 0.060 \\
\hline K2 & K6 & 14.100 & 0.455 & 1.647 & 0.700 & 0.624 & 0.114 \\
\hline K3 & K4 & 0.351 & 0.052 & 0.049 & 0.051 & 0.024 & 0.475 \\
\hline K3 & K5 & 4.758 & 0.381 & 0.641 & 0.522 & 0.543 & 0.280 \\
\hline K3 & K6 & 8.026 & 0.409 & 0.924 & 0.533 & 0.570 & 0.200 \\
\hline K4 & K5 & 6.587 & 0.411 & 0.619 & 0.616 & 0.599 & 0.237 \\
\hline K4 & K6 & 9.800 & 0.431 & 0.882 & 0.622 & 0.631 & 0.068 \\
\hline K5 & K6 & 8.624 & 0.577 & 1.324 & 0.740 & 0.340 & 0.070 \\
\hline \multicolumn{2}{|c|}{ Global pairwise genetic distance } & - & 0.333 & 0.771 & 0.560 & 0.469 & - \\
\hline
\end{tabular}




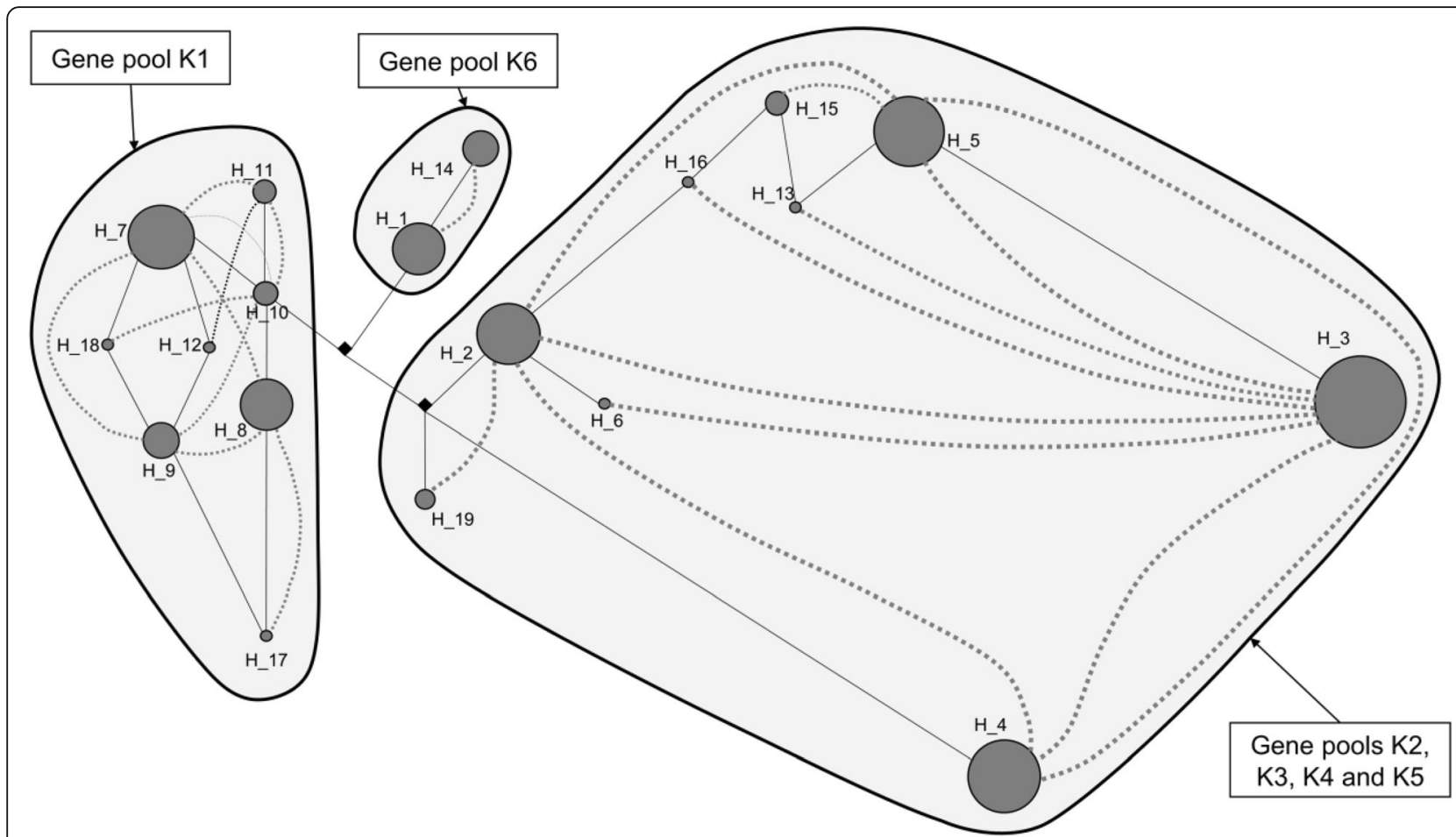

Fig. 4 At103 haplotype network and haploweb (sensu [8]) in the genus Milicia. Circles that stand for each haplotype (H_1, H_2, etc.) are proportional to the number of individuals. The length between a pair of haplotypes is proportional to the number of mutations separating them. Dashed curves link together haplotypes of heterozygous individuals. Each surrounded group of haplotypes indicates a single-locus field for recombination (FFR) and the corresponding genetic clusters (K1 to K6) are mentioned beside. Individuals of the morphospecies $M$. regia are exclusively found in two genetic clusters, K1 (West African trees) and K6 (Central African trees)

cluster K2 than with the conspecific cluster K6 (Figs. 5b and c). The three phylogenetic trees agreed to identify the cluster $\mathrm{K} 6$ as the most divergent group. With microsatellite loci, the most ancient split was detected between K2 and K6, dated between $0.07-1.41$ mya.

\section{Niche overlap between Milicia genetic clusters and correlation with genetic distance}

The occurrence range of the six genetic clusters was well explained by the following climatic variables correlated to the first PCA axis (68.5\% of the total variance): annual mean precipitation, annual mean temperature, annual temperature range, solar radiation, and precipitation of the driest quarter (Additional file 1: Figure S7). The niche model map of each genetic cluster is presented in the Additional file 1: Figure S8. Globally, niche overlap values were low, ranging between 0.060 (K2-K5) and 0.475 (K3-K4) (Table 3). The Mantel test between niche overlap values $D$ and the genetic distance $D_{\mathrm{S}}$ resulted in a regression slope $b=-0.131(R=-0.39)$ which was not significant $(P=0.159)$. A similar analysis using $D$ and $(\delta \mu)^{2}$ resulted in $b=-0.022(R=-0.581)$ which was significant $(P=0.016)$.

\section{Discussion}

According to the sampling scheme and the markers used genetic studies can either detect or miss hidden genetic diversity. In particular the sampling approach may be a major issue. Daïnou et al. [26] did not highlight any particular genetic species specificity from a sample of 849 individuals of Milicia because their sampling was not spatially regular (overrepresentation of some locations). Owing to new populations included in the analyses and a more homogeneous geographic sampling with a lower number of individuals (535 individuals), we showed that both SSRs and a few dozens of SNPs are good marker candidates to reliably characterize the genetic structure within a taxon.

As hypothesized, East African populations of Milicia excelsa strongly diverge from the Central and West African populations, a pattern found in other species $[28,59]$, and mirrored by the clear differentiation of the East Africa flora compared to the remainder of the continent (e.g. [60]). But the most important finding came from the Milicia genetic cluster K6 made of scattered Central African samples morphologically similar to $M$. regia. This species is known to occur only in West Africa westwards of Togo, hence one may think that 
(A)

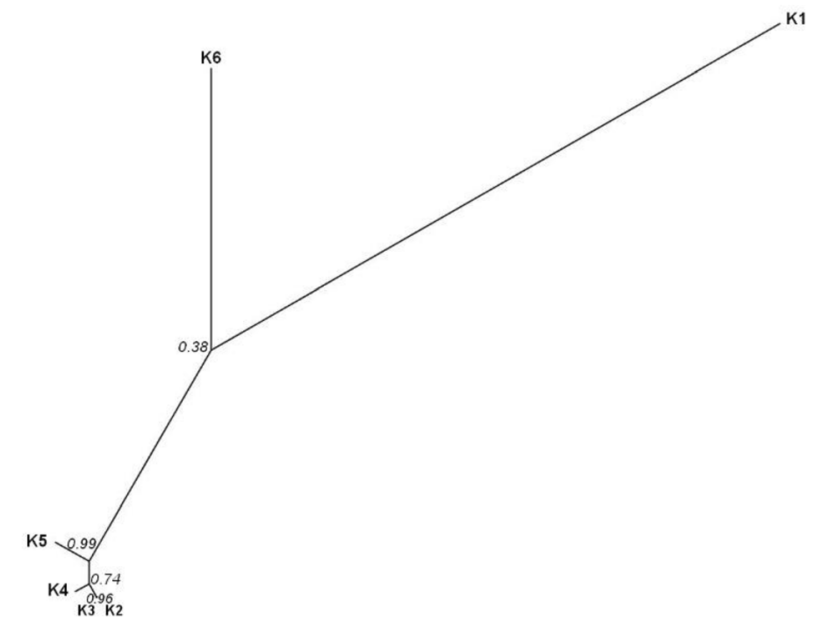

(B)

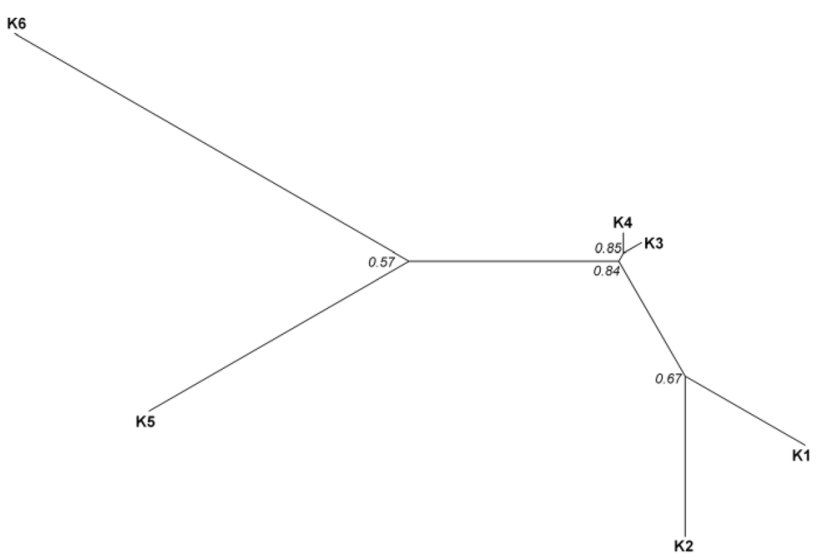

(C)

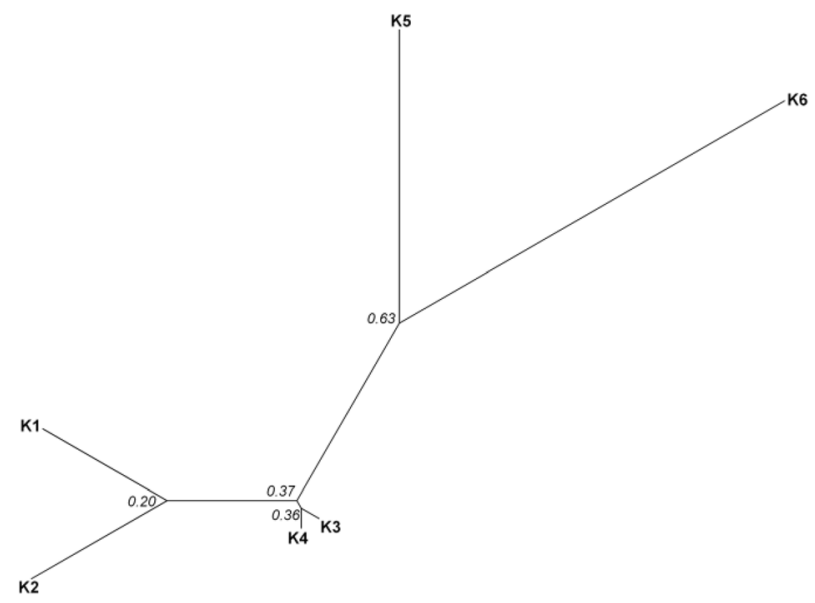

Fig. 5 Phylogenetic trees from Milicia genetic clusters. The trees were constructed from At103 sequences (a), genetic distances $D_{S}$ based on nuclear microsatellite genotypes (b) and SNPs dataset (c) considering the genetic clusters (K1 to K6). Italic number at the nodes indicate posterior probabilities (a) or bootstrap values (b and $\mathbf{c}$ ) 
these individuals could be remnants of historical plantations of M. regia (as supported by SNPs). However, we found no report of such plantations, while we rediscovered a century-old article reporting $M$. regia in Gabon [27]. Further investigations using other markers confirmed that the morphospecies $M$. regia observed in Central Africa is strongly divergent from the other populations of Milicia: (i) the clustering pattern from SSRs that considered this group as a different genetic cluster; (ii) the absence of gene flow with the other clusters; and (iii) the haploweb outputs from the nuclear sequence At103 that identified all these K6-individuals as a separate field for recombination. Furthermore, phylogenetic reconstructions suggested that the genetic cluster K6 is probably as old as the ancestors of all Milicia populations. Divergence among Milicia genetic clusters looks to have been shaped by geographic isolation probably in relation to past ice ages but there was also a signal of habitat selection effect (significant correlation between niche overlap and the genetic distance $\left.(\delta \mu)^{2}\right)$.

\section{Discovering hidden genetic diversity: beyond the sampling scheme are the type of markers and the analytical tools}

In case of weak morphological differentiation among taxa the discovery of cryptic species is most of the time a matter of chance [61], unless there is some observation-based evidence of lack of mating between the sibling groups (e.g., $[62,63])$. At the beginning of the $21^{\text {st }}$ century, barcoding techniques were used to detect hidden genetic diversity in the form of two or more phylogenetically distinct clades corresponding to slightly different phenotypic groups or having distinct geographical distributions $[6,64]$. The advantage of sequence data is that they require a low sampling density although it has been criticized [65]. Detection of polyphyletic patterns may only be conclusive by maximizing the number of samples per geographical location and the number of places for collection. The major limit of phylogenetic approaches based on sequence data in addressing cryptic species issues is that the observation of paraphyly or polyphyly does not allow to identify species although reproductively isolated groups may exist. In the absence of population genetics data additional information such as allopatric distribution, substantial differences in morphology (preferably qualitative characters; [7]) or any other observations suggesting mating barrier may be necessary to argue for the presence of cryptic species [6, 66-68]. As a consequence the haploweb approach looks as a good alternative for species delimitation.

Species delimitation via haplowebs has been proved to be better than coalescent approaches or gap detection method in species-poor data sets (one to three species; [10]). However, haplowebs can also provide biased conclusions when population sizes and speciation rates are large
[10]. Milicia is not a young genus [26] and as it is known to contain only a few species (two species before the present study), we can argue that rapid radiation is not relevant here and should not affect performance of haploweb. But dense sampling can be a concern: more heterozygous individuals may contain rare shared alleles which may obscure the global pattern, leading to underestimation of the true number of species. With the exception of the cluster K6, sample size per genetic cluster was quite high in the present study ranging from 30 to 197 . That putative problem can be solved by using several independent markers for constructing the haplowebs, but this was not possible in our case because only one of the 12 tested nuclear sequences was polymorphic. Specific haplotypes from the two chloroplast sequences were found for only one genetic cluster: the West African populations of $M$. regia. Although not employed as much as trnH-psbA, trnC-ycf6 got a certain success when combined with the former (e.g., [69]). trnH-psbA is probably the most used plastid intergenic barcode after $r b c L+m a t K$ [70] and shows good species identification success rates [71] including in Moraceae such as Ficus [72]. Therefore it can be useful when aiming at revealing hidden species diversity (e.g. [73]). But it failed in the case of Milicia.

\section{Milicia evolutionary history and incongruence between gene genealogies}

Haplotype sharing between the cluster K6 and M. excelsa individuals from chloroplast sequences may suggest either a strong relatedness between those populations along with incomplete lineage sorting, or past chloroplast capture. If we remove from consideration the West African cluster of $M$. regia $\mathrm{K} 1$, the divergence time of $\mathrm{K} 6$ and its relatedness to Kenyan cluster $\mathrm{K} 5$ composed of $M$. excelsa (Fig. $5 \mathrm{~b}$ and c) supported the first hypothesis as this phenomenon is quite common in recently diverging species with large effective population size [74]. The chloroplast capture scenario is also acceptable. It is a common phenomenon between closely related plant species, and there are already several examples that are explained by such events (e.g. [75]). Theory predicts that when a species extends into the range of a related species that can occasionally hybridize, a hybridisation event followed by recurrent backcrosses can lead to the capture of the chloroplast of the local species by the invading one [76]. We can thus hypothesise that this had happened in the past when ancestors of $K 6$ penetrated the range of M. excelsa in Central Africa. Additional investigations with new markers could help to identify the best scenario.

Niche modelling techniques offer a good way to verify relationships between population genetic divergence and environmental selection. Daïnou et al. [26] already developed a scenario on the possible impact of past climate changes on population demography in Milicia. The Mantel test 
between $(\delta \mu)^{2}$ and niche overlap $D$ performed in the present study resulted in a substantial and significant correlation $(R=-0.58)$. This should reflect signs of selection acting for the differentiation between the genetic clusters of Milicia, even at intraspecific level for M. excelsa [32], and this took place many thousands of years before as the modelling of niches was based on climatic data from the Last Glacial Maximum $(\approx 20,000 \mathrm{BP})$. We need to moderate the value of the correlation as the outcomes of niche modelling for some Milicia genetic clusters could be unreliable or incomplete. Indeed, the outputs of those approaches, especially Maxent technique, can be biased by samples provided for the modelling [77]. The West African samples implemented here in the environmental modelling was poor as it covered only a few countries whereas the genus occurs from Senegal to Nigeria in that region. Therefore, we do think that further investigations related to niche characteristics should be conducted later in order to better assess signs of any putative selection effect on genetic cluster differentiation.

\section{SNPs vs SSRs: high congruence for the contemporaneous genetic structure but divergent histories}

Due to the biallelic character of most of SNPs these markers are usually considered as less informative than polymorphic microsatellites to highlight a genetic structure, for a similar number of loci. Hess et al. [22] found that SNP loci may require 8-15 times the number of SSR loci to delineate with equivalent power a mixture of individuals from differentiated populations (see also [78]). As our number of SNP loci was 9.6 times the number of microsatellites markers, we could thus expect similar power. It is probably more relevant to compare the total number of alleles minus the number of loci between the two set of markers, which gives 134-67 = 67 for SNPs and $65-7=58$ for SSRs. Thus, there would be a slight advantage for our set of SNPs. Accordingly, in West Africa, SNPs performed well to delineate the two species whereas SSRs exhibited a substantial proportion of putatively admixed individuals that may reflect a more limited power of SSRs to separate species, unless hybridization is more pronounced than assumed between $M$. excelsa and $M$. regia in West Africa (SSRs better detect admixed individuals; [16]). However, SNPs systematically merged K6individuals with West African $M$. regia individuals up to $K_{\max }=7$ (not shown; signs of separation between $K 6$ and $\mathrm{K} 1$ appeared at $K_{\max }=8$ ). As the clustering solution of SSRs was clearly supported by the At103 sequences that demonstrated that K6 bears exclusive haplotypes, SNPs appeared less powerful than SSRs to discriminate genetic clusters in Central Africa.

Another important difference between SSRs and SNPs was observed in the trend of genetic diversity among genetic clusters for each type of marker. Whereas SSRs exhibited the highest sequence diversity in the West African $M$. regia cluster $\mathrm{K} 1$ ( $\mathrm{He}=0.72$ compared to $\mathrm{He}$ in the range 0.32 to 0.54 for the other genetic clusters), SNPs displayed much lower diversity values in both $M$. regia clusters $\mathrm{K} 1(\mathrm{He}=0.06)$ and $\mathrm{K} 6(\mathrm{He}=0.03)$ as compared to $M$. excelsa genetic clusters ( $\mathrm{He}$ in the range 0.12 to 0.33 ). Ascertainment biases due to marker discovery protocols can explain those differences. In microsatellites, the hypothesis of length ascertainment bias states that the median or mean allele size of microsatellites is the greatest in the species or population that has served for the development of the markers. Homologous loci in sister species may have different evolutionary histories so that a locus characterized in a sister species may not be as polymorphic as in the one from which SSRs have been derived [79]. In the present case, the SSR markers have been identified from a Milicia excelsa individual (sampled in the area of $\mathrm{K} 2$ ) and their polymorphism was evaluated in a sample composed of 30 trees of $M$. excelsa and 10 of M. regia from Ghana [80]. First, only three of the used SSR loci displayed a mean higher allele size in K2 comparatively to the other genetic clusters. Second, as the highest SSR diversity was not found in the cluster $\mathrm{K} 2$, there is no evidence of ascertainment bias in our SSR dataset. In fact, due to their high mutation rates, SSRs tend to be buffered from ascertainment bias comparatively to SNPs [23]. The SNP markers used in the present work have been identified from two $M$. excelsa individuals from $\mathrm{K} 2$ and $\mathrm{K} 5$, and the step of polymorphism screening for final marker selection involved only $17 \%$ of West African $M$. regia trees (C. Blanc-Jolivet and B. Degen, in preparation). As by definition SNPs are identified based on their polymorphism in the initially screened samples, ascertainment bias can be strong and this likely explains the much lower genetic diversity recorded in $M$. regia populations. As a SNP generally results from a unique mutation event and SNPs were assessed between the M. excelsa populations $\mathrm{K} 2$ and $\mathrm{K} 5$, only polymorphisms that appeared before the differentiation between $M$. excelsa and $M$. regia could remain polymorphic in both species. A comparison of SNP loci in morphologically assigned $M$. regia genetic clusters showed that among the 48 loci which were polymorphic in $\mathrm{K} 1$, only 14 were also polymorphic in K6. Only one locus was found polymorphic in $\mathrm{K} 6$ and not in K1. This clear ascertainment bias highlights that particular care should be made for the selection of SNPs for genetic structure characterization and that starting from a broad genetic basis is preferable.

\section{Conclusions}

The present work highlights the value of large-scale genotyping of genera to discover cryptic species as well as highlight their hidden diversity at the intra-specific 
level. It is notable that, for a well-known timber tree, the occurrence of two species in Central Africa was not reported by botanists for a century although diagnostic leaf characters were known. Additional morphological investigations are required to evaluate at which extent the Central African new species of Milicia phenotypically resemble to the other species. In particular, floral and fruit characters should be meticulously examined. Additional file 1: Table S2 provides a list of individuals that were identified a priori in this new species, taking into account the entire sample of the ITTO Project. Because our sampling was not performed in a way that rare hybrids would be detected, next samplings should target the contact zones between the three species in order to verify more thoroughly any interspecific hybridization pattern.

We suspect that many similar cases remain, and that the floristic diversity of tropical forests remains underestimated. Recognizing cryptic species is particularly important for exploited species, like timber trees, as some of them might be endangered and require a special management policy while they are currently confused with a less vulnerable species. To identify cryptic species we showed that nuclear SNPs and SSRs can both be utilized and show similar resolution, while plastid markers are less reliable, a problem for current DNA barcoding in plants based on $r b c L+$ matK sequencing. However, SNPs are prone to ascertainment bias than SSRs, at least when assessing genetic diversity, so that their development should ideally start from a large sample size. We recommend to collect and genotype hundreds of samples covering the distribution range of the taxon investigated.

\section{Additional file}

Additional file 1: Table S1. Polymorphic (1) and monomorphic (0) SNP loci (P0040, P0095, etc.) in the six genetic clusters of Milicia (K1 to K6). Table S2. Geographic coordinates of Central African individuals of Milicia that may represent a new species according to SNP and based on the whole Milicia sample of the ITTO Project PD 620/11 Rev.1 (M): "Development and implementation of species identification and timber tracking in Africa with DNA fingerprints and stable isotopes" (1833 individuals). Individuals in bold are those selected for the SNP-SSR comparison (435 individuals in total) and which all turned out to be representatives of a new species as the nuclear gene At103 confirmed. Figure S1. Determination of the number of genetic clusters in Milicia populations based on SNPs genotypes. Figure S2. Determination of the number of clusters in Milicia populations based on SSRs genotypes. Figure S3. (A) Lower surface of leaf for a tree morphologically identified as $M$. regia in Central Africa and confirmed by molecular markers, compared to a neighbour tree with typical leaves of M. excelsa (B). Figure S4. Graphical membership coefficient of Central African individuals of Milicia (genetic clusters K3 to K6) based on nuclear SSR loci. The six colours (blue, black, yellow, pink, green and red) stand for the six genetic clusters. The West African genetic clusters, K1 and $\mathrm{K} 2$, were not illustrated but were represented in some individual genome (blue and dark colors). Figure S5. Haplotype network and geographical distribution of trnH-psbA haplotypes in Milicia populations. Figure S6. Haplotype network and geographical distribution of trnC-ycf6 haplotypes in Milicia populations. Figure S7. Ecological niches of the six genetic clusters of Milicia derived from nuclear SSR loci, in the environmental space produced by the principal component analysis method (PCA). The figure above indicates projection of the climatic variables in the plan formed by the two first axes $(71.9 \%$ of the total variance). Similarly, the grey-to-black shading in the six small figures ( 1 = cluster $\mathrm{K} 1 ; 2$ = cluster $\mathrm{K} 2$; etc.) represents the grid cell density (black being the highest density) of the concerned genetic cluster in the PCA plan. The first dashed curve represents the $50 \%$ of the available environment space whereas the solid line stands for the entirety of the species environment. Figure S8. Potential distribution range of Milicia genetic clusters during the Last Glacial Maximum (LGM) according to niche modelling through Maxent approach. Black areas represent predicted regions with a probability higher than 50\%. (DOCX 1353 kb)

\section{Acknowledgements}

Part of the experiments presented in the present publication (SNP genotyping) were performed at the Genomic and Sequencing Facility of Bordeaux (grants from the Conseil Regional d'Aquitaine $n^{\circ} 20030304002 F A$ and 20040305003 FA and from the European Union, FEDER n ${ }^{\circ} 2003227$ and from "Investissements d'avenir, Convention attributive d'aide NANR-10-EQPX16-01"). The work was financially supported by the International Tropical Timber Organization (ITTO) through the projects PD 620/11 Rev.1 (M): "Development and implementation of species identification and timber tracking in Africa with DNA fingerprints and stable isotopes", Förderkennzeichen 281-001-01: "Large scale project on genetic timber verification", and the project T.0163.13 (F.R.S.-FNRS). We thank Jean-François Flot for constructive comments on the way to treat sequences of length variant heterozygotes.

\section{Availability of data and materials}

Milicia sequences at the nuclear region At103 have been deposited in GenBank under the accession numbers KX832114-KX832132. The nuclear microsatellites data will be deposited in DRYAD. Nuclear SNP data belong to the Thünen Institute for Forest Genetics (Germany) and will be made available by Bernd Degen and Céline Blanc-Jolivet. All other supporting data are included as Additional files.

\section{Authors' contributions}

$\mathrm{KD}$ and $\mathrm{OH}$ conceived the study, performed computer analyses and drafted the manuscript. Sample collection was managed by NB. BD and CBJ developed and provided SNP markers. EK, PK, ASD, DNB and FT contributed to the laboratory works, data treatment and analyses. JLD supervised the study. All authors revised and approved the final manuscript.

\section{Competing interests}

The authors declare that they have no competing interests.

\section{Author details}

${ }^{1}$ Nature + asbl / TERRA Research Centre, Central African Forests, Gembloux Agro-Bio Tech, University of Liege, Passage des Déportés 2, 5030 Gembloux, Belgium. ${ }^{2}$ Université d'Agriculture de Kétou, BP 43, Kétou, Benin. ${ }^{3}$ Thünen Institute of Forest Genetics, Sieker Landstrasse 2, 22927 Grosshansdorf, Germany. ${ }^{4}$ Kenya Forestry Research Institute, Biotechnology Section, P. O. Box 20412-00200 Nairobi, Kenya. IRAF/CENAREST, BP 842 Gros-bouquet, Libreville, Gabon. ${ }^{6}$ TERRA Research Centre, Central African Forests, Gembloux Agro-Bio Tech, University of Liege, Passage des Déportés 2, 5030 Gembloux, Belgium. 'Evolutionary Biology and Ecology - CP 160/12, Faculté des Sciences, Université Libre de Bruxelles, Av. F. Roosevelt 50, 1050 Brussels, Belgium. ${ }^{8}$ Service of Wood Biology, Royal Museum for Central Africa, Tervuren, Belgium.

Received: 11 February 2016 Accepted: 17 November 2016 Published online: 01 December 2016

References

1. White GB. The place of morphological studies in the investigation of Anopheles species complexes. Mosquito Systematics 1977;9:1-24. 
2. Bickford D, Lohman DJ, Sodhi NS, Ng PK, Meier R, Winker K, Ingram KK, Das I. Cryptic species as a window on diversity and conservation. Trends Ecol Evol. 2006;22(3):148-55.

3. Carstens BC, Pelletier TA, Reid NM, Satler JD. How to fail at species delimitation. Mol Ecol. 2013;22(17):4369-83.

4. Grattepanche JD, Santoferrara LF, McManus GB, Katz LA. Diversity of diversity: conceptual and methodological differences in biodiversity estimates of eukaryotic microbes as compared to bacteria. Trends Microbiol. 2014;22(8):432-7.

5. Scheffers BR, Joppa LN, Pimm SL, Laurance WF. What we know and don't know about Earth's missing biodiversity. Trends Ecol Evol. 2012;27(9):501-10.

6. Funk DJ, Omland KE. Species-level paraphyly and polyphyly: frequency, causes, and consequences, with insights from animal mitochondrial DNA. Annu Rev Ecol Evol S. 2003;34(1):397-423.

7. Zachos FE, Apollonio M, Bärmann EV, Festa-Bianchet M, Göhlich U, Habel JC, Haring E, Kruckenhauser L, Lovari S, McDevitt AD, et al. Species inflation and taxonomic artefacts - a critical comment on recent trends in mammalian classification. Mammal Biol. 2013;78(1):1-6

8. Flot JF, Couloux A, Tillier S. Haplowebs as a graphical tool for delimiting species: a revival of Doyle's "field for recombination" approach and its application to the coral genus Pocillopora in Clipperton. BMC Evol Biol. 2010;10:372.

9. Doyle JJ. The irrelevance of Allele Tree topologies for species delimitation, and a non-topological alternative. Syst Bot. 1995;20(4):574-88.

10. Dellicour S, Flot JF. Delimiting species-poor data sets using single molecular markers: a study of barcode gaps, haplowebs and GMYC. Syst Biol. 2015; 64(6):900-8.

11. Duminil J, Caron H, Scotti I, Cazal SO, Petit RJ. Blind population genetics survey of tropical rainforest trees. Mol Ecol. 2006;15(12):3505-13.

12. Schmidt-Roach S, Lundgren P, Miller KJ, Gerlach G, Noreen AME, Andreakis $\mathrm{N}$. Assessing hidden species diversity in the coral Pocillopora damicornis from Eastern Australia. Coral Reefs. 2012;32(1):161-72.

13. Parmentier I, Duminil J, Kuzmina M, Philippe M, Thomas DW, Kenfack D, Chuyong GB, Cruaud C, Hardy OJ. How effective are DNA barcodes in the identification of African rainforest trees. PLoS One. 2013;8(4):e54921.

14. Petit RJ, Excoffier L. Gene flow and species delimitation. Trends Ecol Evol. 2009;24(7):386-93.

15. Twyford AD, Ennos RA. Next-generation hybridization and introgression. Heredity 2012;108(3):179-89.

16. Guichoux E, Lagache L, Wagner S, Chaumeil P, Leger P, Lepais $O$, Lepoittevin C, Malausa T, Revardel E, Salin F, et al. Current trends in microsatellite genotyping. Mol Ecol Resour. 2011;11(4):591-611.

17. DeFaveri J, Viitaniemi H, Leder E, Merila J. Characterizing genic and nongenic molecular markers: comparison of microsatellites and SNPs. Mol Ecol Resour. 2013;13(3):377-92.

18. Granevitze Z, David L, Twito T, Weigend S, Feldman M, Hillel J. Phylogenetic resolution power of microsatellites and various single-nucleotide polymorphism types assessed in 10 divergent chicken populations. Anim Genet. 2014:45(1):87-95.

19. Forstmeier W, Schielzeth $H$, Mueller JC, Ellegren $H$, Kempenaers B. Heterozygosity-fitness correlations in zebra finches: microsatellite markers can be better than their reputation. Mol Ecol. 2012;21(13):3237-49.

20. Ljungqvist $M$, Åkesson $M$, Hansson B. Do microsatellites reflect genomewide genetic diversity in natural populations? A comment on Väli et al. (2008). Mol Ecol. 2010;19(5):851-5.

21. Morin PA, Luikart G, Wayne RK, the SNPwg. SNPs in ecology, evolution and conservation. Trends Ecol Evol. 2004;19(4):208-16.

22. Hess JE, Matala AP, Narum SR. Comparison of SNPs and microsatellites for fine-scale application of genetic stock identification of Chinook salmon in the Columbia River Basin. Mol Ecol Resour. 2011;11 Suppl 1:137-49.

23. Lachance J, Tishkoff SA. SNP ascertainment bias in population genetic analyses: why it is important, and how to correct it. Bioessays. 2013;35(9):780-6.

24. Daïnou K, Doucet JL, Sinsin B, Mahy G. Identité et écologie des espèces forestières commerciales d'Afrique centrale: le cas de Milicia spp. Biotechnol Agron Soc. 2012;16(2):229-41

25. Dainou K, Laurenty E, Mahy G, Hardy OJ, Brostaux Y, Tagg N, Doucet JL. Phenological patterns in a natural population of a tropical timber tree species, Milicia excelsa (Moraceae): Evidence of isolation by time and its interaction with feeding strategies of dispersers. Am J Bot. 2012;99(9):1453-63.

26. Daïnou K, Mahy G, Duminil J, Dick C, Doucet J-L, Donkpégan A, Pluijgers M, Sinsin B, Lejeune P, Hardy OJ. Speciation slowing down in widespread and long-living tree taxa: insights from the tropical timber tree genus Milicia (Moraceae). Heredity. 2014;113(1):74-85.

27. Chevalier A. Les végétaux utiles d'Afrique tropicale française - La forêt et les bois du Gabon. Paris: Challamel; 1917

28. Kadu C, Schueler S, Konrad H, Muluvi G, Eyog-Matig O, Muchugi A, Williams V, Ramamonjisoa L, Kapinga C, Foahom B. Phylogeography of the Afromontane Prunus africana reveals a former migration corridor between East and West African highlands. Mol Ecol. 2011;20(1):165-78.

29. Diallo BO, Joly HI, McKEY D, Hosaert-McKey M, Chevallier MH. Genetic diversity of Tamarindus indica populations: Any clues on the origin from its current distribution? Afr J Biotechnol. 2007, 6(7):853-60.

30. Fogelqvist J, Niittyvuopio A, Ågren J, Savolainen O, Lascoux M. Cryptic population genetic structure: the number of inferred clusters depends on sample size. Mol Ecol Resour. 2010;10(2):314-23.

31. McKay JK, Latta RG. Adaptive population divergence: markers, QTL and traits. Trends Ecol Evol. 2002;17(6):285-91.

32. Nosil P, Funk DJ, Ortiz-Barrientos D. Divergent selection and heterogeneous genomic divergence. Mol Ecol. 2009;18(3):375-402

33. Degen B, Bouda H. Verifying timber in Africa. ITTO Trop Forest Update. 2015, 24(1):8-10

34. Bizoux JP, Dainou K, Bourland N, Hardy OJ, Heuertz M, Mahy G, Doucet JL. Spatial genetic structure in Milicia excelsa (Moraceae) indicates extensive gene dispersal in a low-density wind-pollinated tropical tree. Mol Ecol. 2009. 18(21):4398-408

35. Dainou K, Bizoux JP, Doucet JL, Mahy G, Hardy OJ, Heuertz M. Forest refugia revisited: nSSRs and cpDNA sequences support historical isolation in a wide-spread African tree with high colonization capacity, Milicia excelsa (Moraceae). Mol Ecol. 2010;19(20):4462-77.

36. Jardine D, Blanc-Jolivet C, Dixon R, Dormontt E, Dunker B, Gerlach J, Kersten B, van Dijk K-J, Degen B, Lowe A. Development of SNP markers for Ayous (Triplochiton scleroxylon K. Schum) an economically important tree species from tropical West and Central Africa. Conserv Genet Resour 2016:8:129-39.

37. Li M, Wunder J, Bissoli G, Scarponia E, Gazzani S, Barbaro E, Saedler H, Varotto C. Development of COS genes as universally amplifiable markers for phylogenetic reconstructions of closely related plant species. Cladistics. 2008;24:727-45

38. Chen C, Durand E, Forbes F, FranÇOis O. Bayesian clustering algorithms ascertaining spatial population structure: a new computer program and a comparison study. Mol Ecol Notes. 2007;7(5):747-56

39. Jakobsson M, Rosenberg NA. Clumpp: a cluster matching and permutation program for dealing with label switching and multimodality in analysis of population structure. Bioinformatics. 2007;23:1801-6.

40. Hardy OJ, Vekemans X. Spagedi: a versatile computer program to analyse spatial genetic structure at the individual or population levels. Mol Ecol Notes. 2002:2:618-20.

41. Nielsen R, Tarpy DR, Reeve HK. Estimating effective paternity number in social insects and the effective number of alleles in a population. Mol Ecol. 2003;12(11):3157-64

42. Goldstein DB, Linares AR, Cavalli-Sforza LL, Feldman MW. An evaluation of genetic distances for use with microsatellite loci. Genetics. 1995;139(1):463-71.

43. Sun JX, Mullikin JC, Patterson N, Reich DE. Microsatellites are molecular clocks that support accurate inferences about history. Mol Biol Evol. 2009; 26(5):1017-27.

44. Ochieng JW, Steane DA, Ladiges PY, Baverstock PR, Henry RJ, Shepherd M Microsatellites retain phylogenetic signals across genera in eucalypts (Myrtaceae). Genet Mol Biol. 2007;30(4):1125-34.

45. Takezaki N, Nei M, Tamura K. POPTREE2: Software for constructing population trees from allele frequency data and computing other population statistics with Windows interface. Mol Biol Evol. 2010;27(4):747-52.

46. Goldstein D, Pollock D. Mutation processes and methods of phylogenetic inference. J Hered. 1997;88:335-42.

47. Li YC, Korol AB, Fahima T, Beiles A, Nevo E. Microsatellites: genomic distribution, putative functions and mutational mechanisms: a review. Mol Ecol. 2002;11(12): 2453-65.

48. Vigouroux Y, Jaqueth JS, Matsuoka Y, Smith OS, Beavis WD, Smith JSC, Doebley J. Rate and pattern of mutation at microsatellite loci in maize. Mol Biol Evol. 2002;19(8):1251-60.

49. Bandelt H-J, Forster $\mathrm{P}$, Röhl A. Median-Joining networks for inferring intraspecific phylogenies. Mol Biol Evol. 1999;16(1):37-48.

50. Librado P, Rozas J. DnaSP v5: a software for comprehensive analysis of DNA polymorphism data. Bioinformatics. 2009;25(11):1451-2. 
51. Flot J-F. Champuru 1.0: a computer software for unraveling mixtures of two DNA sequences of unequal lengths. Mol Ecol Notes. 2007;7(6):974-7.

52. Heled J, Drummond AJ. Bayesian inference of species trees from multilocus data. Mol Biol Evol. 2010;27(3):570-80.

53. Phillips SJ, Anderson RP, Schapire RE. Maximum entropy modeling of species geographic distributions. Ecol Model. 2006;190(3):231-59.

54. Hijmans RJ, Cameron SE, Parra $J$, Jones PG, Jarvis A. Very high resolution interpolated climate surfaces for global land areas. Int J Climatol. 2005; 25(15):1965-78.

55. Heikkinen RK, Luoto M, Araújo MB, Virkkala R, Thuiller W, Sykes MT. Methods and uncertainties in bioclimatic envelope modelling under climate change. Prog Phys Geogr. 2006;30(6):751-77.

56. R Development Core Team. R, A language and environment for statistical computing. Available: http://www.R-project.org. Accessed 2015 May.

57. Broennimann O, Fitzpatrick MC, Pearman PB, Petitpierre B, Pellissier L, Yoccoz NG, Thuiller W, Fortin M-J, Randin C, Zimmermann NE, et al. Measuring ecological niche overlap from occurrence and spatial environmental data. Glob Ecol Biogeogr. 2012;21(4):481-97.

58. Schoener TW. The Anolis lizards of Bimini: resource partitioning in a complex fauna. Ecology. 1968;49(4):704-26.

59. Odee DW, Telford A, Wilson J, Gaye A, Cavers S. Plio-Pleistocene history and phylogeography of Acacia senegal in dry woodlands and savannahs of subSaharan tropical Africa: evidence of early colonisation and recent range expansion. Heredity. 2012. In press.

60. Linder H. Plant diversity and endemism in sub-Saharan tropical Africa. J Biogeogr. 2001;28(2):169-82.

61. Furman A, Postawa T, Oztunc T, Coraman E. Cryptic diversity of the bentwing bat, Miniopterus schreibersii (Chiroptera: Vespertilionidae), in Asia Minor. BMC Evol Biol. 2010;10:121.

62. Yoder AD, Burns MM, Génin F. Molecular evidence of reproductive isolation in sympatric sibling species of mouse lemurs. Int J Primatol. 2002;23(6):1335-43.

63. Hebert PD, Penton EH, Burns JM, Janzen DH, Hallwachs W. Ten species in one: DNA barcoding reveals cryptic species in the neotropical skipper butterfly Astraptes fulgerator. Proc Natl Acad Sci U S A. 2004;101(41):14812-7.

64. Liu J, Moller M, Gao LM, Zhang DQ, Li DZ. DNA barcoding for the discrimination of Eurasian yews (Taxus L., Taxaceae) and the discovery of cryptic species. Mol Ecol Resour. 2011;11(1):89-100.

65. Bergsten J, Bilton DT, Fujisawa T, Elliott M, Monaghan MT, Balke M, Hendrich L, Geijer J, Herrmann J, Foster GN. The effect of geographical scale of sampling on DNA barcoding. Syst Biol. 2012. doi: 10.1093/sysbio/sys037.

66. Will KW, Mishler BD, Wheeler QD. The perils of DNA barcoding and the need for integrative taxonomy. Syst Biol. 2005;54(5):844-51.

67. Padial JM, Miralles A, De la Riva I, Vences M. The integrative future of taxonomy. Front Zool. 2010;7:16.

68. Puillandre N, Lambert A, Brouillet S, Achaz G. ABGD, Automatic Barcode Gap Discovery for primary species delimitation. Mol Ecol. 2012:21(8):1864-77.

69. Ramsey J, Robertson A, Husband B. Rapid adaptive divergence in New World Achillea, an autopolyploid complex of ecological races. Evolution. 2008;62(3):639-53.

70. Hollingsworth PM, Graham SW, Little DP. Choosing and using a plant DNA barcode. PLoS One. 2011;6(5):e19254.

71. Kress WJ, Wurdack KJ, Zimmer EA, Weigt LA, Janzen DH. Use of DNA barcodes to identify flowering plants. Proc Natl Acad Sci U S A. 2005;102(23):8369-74.

72. Pang X, Liu C, Shi L, Liu R, Liang D, Li H, Cherny SS, Chen S. Utility of the trnH-psbA intergenic spacer region and its combinations as plant DNA barcodes: A meta-analysis. PLoS One. 2012;7(11):e48833.

73. Steven GN, Subramanyam R. Testing plant barcoding in a sister species complex of pantropical Acacia (Mimosoideae, Fabaceae). Mol Ecol Resour. 2009:9(Suppl s1):172-80.

74. Naciri Y, Linder HP. Species delimitation and relationships: the dance of the seven veils. Taxon. 2015;64(1):3-16.

75. Ley AC, Dauby G, Köhler J, Wypior C, Röser M, Hardy OJ. Comparative phylogeography of eight herbs and lianas (Marantaceae) in central African rainforests. Front Genet. 2014;5:403.

76. Rieseberg LH, Soltis D. Phylogenetic consequences of cytoplasmic gene flow in plants. Evol Trend Plant. 1991;5(1):65-84.

77. Phillips SJ, Dudík M, Elith J, Graham CH, Lehmann A, Leathwick J, Ferrier S. Sample selection bias and presence-only distribution models: implications for background and pseudo-absence data. Ecol Appl. 2009;19(1):181-97.
78. Haasl RJ, Payseur BA. Multi-locus inference of population structure: a comparison between single nucleotide polymorphisms and microsatellites. Heredity. 2011;106(1):158-71.

79. Hutter CM, Schug MD, Aquadro CF. Microsatellite variation in Drosophila melanogaster and Drosophila simulans: a reciprocal test of the ascertainment bias hypothesis. Mol Biol Evol. 1998;15(12):1620-36.

80. Ouinsavi C, Sokpon N, Bousquet J, Newton CH, Khasa DP. Novel microsatellite DNA markers for the threatened African endemic tree species, Milicia excelsa (Moraceae), and cross-species amplification in Milicia regia. Mol Ecol Notes. 2006;6(2):480-3.

\section{Submit your next manuscript to BioMed Central and we will help you at every step:}

- We accept pre-submission inquiries

- Our selector tool helps you to find the most relevant journal

- We provide round the clock customer support

- Convenient online submission

- Thorough peer review

- Inclusion in PubMed and all major indexing services

- Maximum visibility for your research

Submit your manuscript at www.biomedcentral.com/submit 